\title{
Soft tissue sarcomas: introduction to the Virchows Archiv review issue
}

\author{
Louis Guillou • Pancras C. W. Hogendoorn • \\ Fred T. Bosman
}

Received: 15 December 2009/Accepted: 15 December 2009/Published online: 18 February 2010

(C) The Author(s) 2010. This article is published with open access at Springerlink.com

Soft tissue sarcomas constitute a heterogeneous category of neoplasms composed mostly of uncommon tumours of different histology, different biology, and different outcome. Thirty years ago, the diagnosis of these neoplasms was mainly based on morphology coupled with some classical histochemical stains such as periodic acid-Schiff, reticulin, and trichrome stains. In the last 15 years, thanks to the substantial development of immunohistochemistry, cytogenetics and molecular genetic analysis significant improvements have been made regarding the classification and diagnosis of these tumors, with direct implications for clinical management and prognosis [1, 2]. Many new entities were recognized of which desmoplastic small round cell tumor and intimal sarcomas are examples. Other sarcoma entities gradually disappeared or lost in importance (e.g., the so-called malignant fibrous histiocytoma [3], hemangiopericytoma [4], and fibrosarcoma categories). During the same period of time, molecular ancillary techniques (including a vast array of polymerase chain reaction-based techniques, fluorescence in situ hybridization (FISH), conventional and array-based comparative genomic hybridization, expression arrays, direct genome sequencing, and DNA methylation analysis to name a few) allowed detailed analysis of these tumors and the resulting data facilitated better understanding of their biology

\footnotetext{
L. Guillou $\cdot$ F. T. Bosman

Department of Pathology, University of Lausanne, Centre Hospitalier Universitaire Vaudois, Pathology, Lausanne, Switzerland

P. C. W. Hogendoorn $(\bowtie)$

Department of Pathology, Leiden University Medical Center, P.O. Box 9600, L1-Q, 2300 RC Leiden, The Netherlands e-mail: p.c.w.hogendoorn@lumc.nl
}

(Fig. 1). In addition, thanks to improvements in nucleic acid preservation and isolation, many molecular techniques provided new parameters important for diagnostics and/or prognosis and were modified to be applicable on formalinfixed, paraffin-embedded material (e.g., FISH, polymerase chain reaction-based techniques). This is all condensed in a substantial revision of the World Health Organization classification which combined histology with genetics [2]. Methodological advances thus allowed better understanding of biology, within turn novel classifications based upon new histogenetic concepts and robust diagnostic methods.

This review issue focuses on the pathobiology of soft tissue sarcomas. In the introductory paper, Bovée and Hogendoorn introduced to the reader the most significant molecular acquisitions that occurred in the domain of sarcomas and their implications for the patient in terms of diagnosis, prognosis, and clinical management [5]. The genomic characteristics of soft tissue sarcomas are exposed in an article of Mertens and coworkers [6]. Here, the authors discuss how the genomic characterization of soft tissue sarcomas has not only provided cell biologists with decisive information on the parts of the genome that may harbor genes that are essential for tumor development, but also given the clinicians involved in the management of these patients a valuable diagnostic tool. Beck et al. share with us the "state of the art" of gene expression profiling in soft tissue sarcomas and how this technique has led to advancements in the understanding of sarcoma pathobiology, the identification of clinically useful biomarkers, and the refinement of sarcoma classification schemes, with hopefully significant benefits to patients [7].

There are two intriguing and highly relevant questions in sarcoma pathobiology: the first one is "why do some people develop sarcomas?" and the second is "from which cells do sarcomas develop?". Recent studies in model systems as 
Fig. 1 Unraveling soft tissue tumors from macroscopy via histology to proteinprofiling and genetics: Macroscopic image of a myxoid soft tissue tumour characterized by its abundant jelly ("myxoid") extracellular matrix on cut surface; histology of grade I myxofibrosarcoma showing sparse tumour cells with slight nuclear atypia in a background of myxoid extracellular matrix with curvilinear bloodvessels $(\times 400)$; imaging mass spectrometry on a tissue slide of grade I myxofibrosarcoma illustrating the heterogeneity in lipid profiles related to their spatial distribution; and combined binary ratio fluorescence in situ hybridization of grade III myxofibrosarcoma with numeric and structural karyotypic aberrations
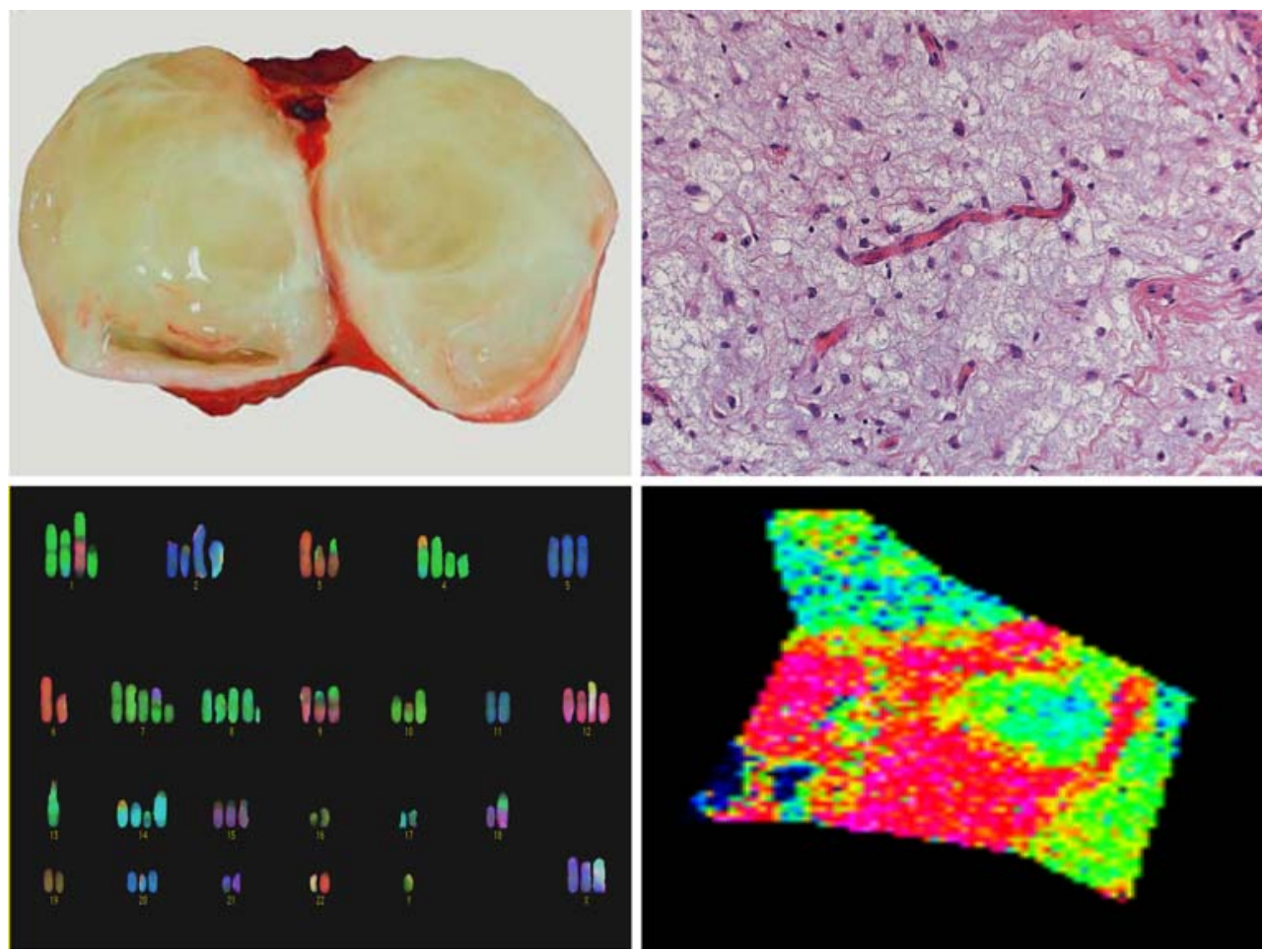

well as on human tumors have provided some answers to these questions and undoubtedly, in the years to come, much of the secrets of mesenchymal stem cells, how they differentiate and how dysregulation of proliferation and differentiation in this system leads to which type of sarcoma [8-15].

Roughly, soft tissue sarcomas can be divided in two categories, those with simple karyotypes and those with complex karyotypes [16]. Of the soft tissue sarcomas (with relatively simple karyotypes), $15-20 \%$ bear specific reciprocal translocations which can be used as diagnostic markers. Some others are characterized by specific somatic mutations (e.g., KIT and platelet-derived growth factor receptor alpha in gastrointestinal stromal tumor (GIST) [17]) or specific amplifications (e.g., MDM2 and CDK4 amplification in the well-differentiated/dedifferentiated liposarcoma category [18]).

For the purposes of this review, sarcomas with specific translocations have been separated into two groups, those involving the Ewing's sarcoma (EWS) gene and those that do not involve the EWS gene. Sarcomas involving EWS translocations (e.g., Ewing's sarcoma, desmoplastic small round cell tumor, etc.) are reviewed by Dei Tos and Romeo [19], whereas genetic and clinicopathological features of soft tissue sarcomas with non EWS translocations (e.g., synovial sarcoma, alveolar rhabdomyosarcoma, etc.) are presented in a comprehensive way by Fisher [20].

In the last 10 years, improvements have been accomplished regarding the diagnosis and pathobiology of well- differentiated/dedifferentiated liposarcomas. Coindre and coworkers summarize for us the most significant advances that occurred in this domain, including the discovery of new promising therapeutic targets [21].

Soft tissue sarcomas with complex karyotypes account for about $50 \%$ of sarcomas. This sarcoma category includes most of spindle cell/pleomorphic sarcomas (myxofibrosarcoma, pleomorphic liposarcoma, etc.) as well as leiomyosarcomas, malignant peripheral nerve sheath tumors, and many other neoplasm's. Guillou and Aurias review their cytogenetic, molecular genetics, and main clinicopathologic characteristics [22]. Most recently, progress in the field of protein chemistry led to a new conceptual approach in order to try to unravel aspecific terms like myxoid matrix (see also Fig. 1). Attempts were made to characterize this matrix $[23,24]$ which turned out to be heterogeneous at the protein level, while morphologically the hallmark of an array of tumor types [25]. Willems et al. discuss the usefulness of such an approach for myxoid matrix containing tumors if explored [26]. Dr. Liegl and coworkers finally discuss the progress made in the understanding of the pathobiology, morphologic evaluation and mechanisms of resistance to tyrosine kinase inhibition in GIST [27]. Gist is one of the examples in oncopathology where the understanding of the genetics of the tumour have lead to major changes in treatment following the development of specific tyrosine kinase blockers [28]. Now we have reached the moment that the subsequent resistant mechanisms which develop in the course of the treatment are of keen interest for 
molecular pathologist and of importance for the patients which have gained years of live quality after treatment of this in the past so aggressive tumor.

For those interested in sarcomas, these are exciting times. We are getting closer to understanding their biology; our diagnoses are better and grow closer to what clinicians need to adequately treat patients. Much remains to be done. We hope that this review issue on the pathobiology of soft tissue sarcomas meets the expectations of the readers of Virchows Archiv. The guest editors warmly thank all the contributors for their effort, willingness, and invaluable input to this work.

Open Access This article is distributed under the terms of the Creative Commons Attribution Noncommercial License which permits any noncommercial use, distribution, and reproduction in any medium, provided the original author(s) and source are credited.

\section{References}

1. Hogendoorn PCW, Collin F, Daugaard S et al (2004) Changing concepts in the pathological basis of soft tissue and bone sarcoma treatment. Eur J Cancer 40:1644-1654

2. Fletcher CDM, Unni KK, Mertens F (2002) WHO classification of tumours. Pathology and genetics of tumours of soft tissue and bone. IARC Press, Lyon

3. Fletcher CDM (1992) Pleomorphic malignant fibrous histiocytoma: fact or fiction? A critical reappraisal based on 159 tumors diagnosed as pleomorphic sarcoma. Am J Surg Pathol 16:213-228

4. Fletcher CDM (1994) Haemangiopericytoma - a dying breed? Reappraisal of an 'entity' and its variants: a hypothesis. Curr Diagn Pathol 1:19-23

5. Bovee JVMG, Hogendoorn PCW (2010) Molecular pathology of sarcomas: concepts and clinical implications. Virchows Arch. doi:10.1007/s00428-009-0828-5

6. Mertens F, Panagopoulos I, Mandahl N (2010) Genomic characteristics of soft tissue sarcomas. Virchows Arch. doi:10.1007/ s00428-009-0736-8

7. Beck AH, West RB, Van de Rijn M (2010) Gene expression profiling for the investigation of soft tissue sarcoma pathogenesis and the identification of diagnostic, prognostic, and predictive biomarkers. Virchows Arch. doi:10.1007/s00428-009-0774-2

8. Mohseny AB, Szuhai K, Romeo S et al (2009) Osteosarcoma originates from mesenchymal stem cells in consequence of aneuploidization and genomic loss of Cdkn2. J Pathol 219:294-305

9. Cironi L, Provero P, Riggi N et al (2009) Epigenetic features of human mesenchymal stem cells determine their permissiveness for induction of relevant transcriptional changes by SYT-SSX1. PLoS ONE 4:e7904

10. Riggi N, Cironi L, Provero P et al (2005) Development of Ewing's sarcoma from primary bone marrow-derived mesenchymal progenitor cells. Cancer Res 65:11459-11468
11. Riggi N, Cironi L, Suva ML et al (2007) Sarcomas: genetics, signalling, and cellular origins. Part 1: the fellowship of TET. J Pathol 213:4-20

12. Riggi N, Cironi L, Provero P et al (2006) Expression of the FUSCHOP fusion protein in primary mesenchymal progenitor cells gives rise to a model of myxoid liposarcoma. Cancer Res 66:7016-7023

13. Riggi N, Suva ML, Suva D et al (2008) EWS-FLI-1 expression triggers a Ewing's sarcoma initiation program in primary human mesenchymal stem cells. Cancer Res 68:2176-2185

14. Suva ML, Cironi L, Riggi N et al (2007) Sarcomas: genetics, signalling, and cellular origins. Part 2: TET-independent fusion proteins and receptor tyrosine kinase mutations. J Pathol 213:117130

15. Suva ML, Riggi N, Stehle JC et al (2009) Identification of cancer stem cells in Ewing's sarcoma. Cancer Res 69:1776-1781

16. Ladanyi M (1995) The emerging molecular genetics of sarcoma translocations. Diagn Mol Pathol 4:162-173

17. Hirota S, Isozaki K, Moriyama Y et al (1998) Gain-of-function mutations in c-kit in human gastrointestinal stromal tumors. Science 279:577-580

18. Dei Tos AP (2001) Lipomatous tumours. Curr Diagn Pathol 7:8-16

19. Romeo S, Dei Tos AP (2010) Soft tissue tumors associated with EWSR1 translocation. Virchows Arch. doi:10.1007/s00428-0090854-3

20. Fisher C (2010) Soft tissue sarcomas with non-EWS translocations: molecular genetic features and pathologic and clinical correlations. Virchows Arch. doi:10.1007/s00428-0090776-0

21. Coindre JM, Pedeutour F, Aurias A (2010) Well-differentiated and dedifferentiated liposarcomas. Virchows Arch. doi:10.1007/ s00428-009-0815-x

22. Guillou L, Aurias A (2010) Soft tissue sarcomas with complex genomic profiles. Virchows Arch. doi:10.1007/s00428-0090853-4

23. Willems SM, Schrage YM, Baelde JJ et al (2008) Myxoid tumours of soft tissue: the so-called myxoid extracellular matrix is heterogeneous in composition. Histopathology 52:465-474

24. Willems SM, Mohseny AB, Balog C et al (2009) Cellular/ intramuscular myxoma and grade I myxofibrosarcoma are characterized by distinct genetic alterations and specific composition of their extracellular matrix. J Cell Mol Med $7: 1301$

25. Graadt van Roggen JF, Hogendoorn PCW, Fletcher CDM (1999) Myxoid tumours of soft tissue. Histopathology 35:291-312

26. Willems SM, Wiweger M, Frans Graadt van Roggen $J$ et al. (2010) Running GAGs: myxoid matrix revisited. What's in it for the pathologist? Virchows Arch. doi:10.1007/s00428-0090822-y

27. Liegl-Atzwanger B, Fletcher JA, Fletcher CMD (2010) Gastrointestinal stromal tumors. Virchows Arch. doi:10.1007/ s00428-010-0891-y

28. Verweij J, van Oosterom A, Blay JY et al (2003) Imatinib mesylate (STI-571 Glivec(R), Gleevec) is an active agent for gastrointestinal stromal tumours, but does not yield responses in other soft-tissue sarcomas that are unselected for a molecular target. Results from an EORTC Soft Tissue and Bone Sarcoma Group phase II study. Eur J Cancer 39:2006-2011 